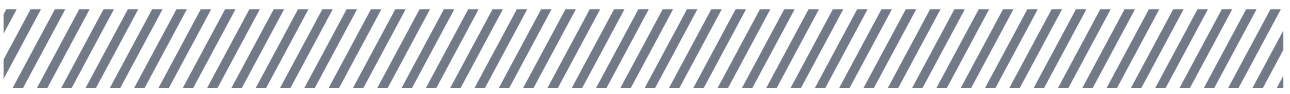

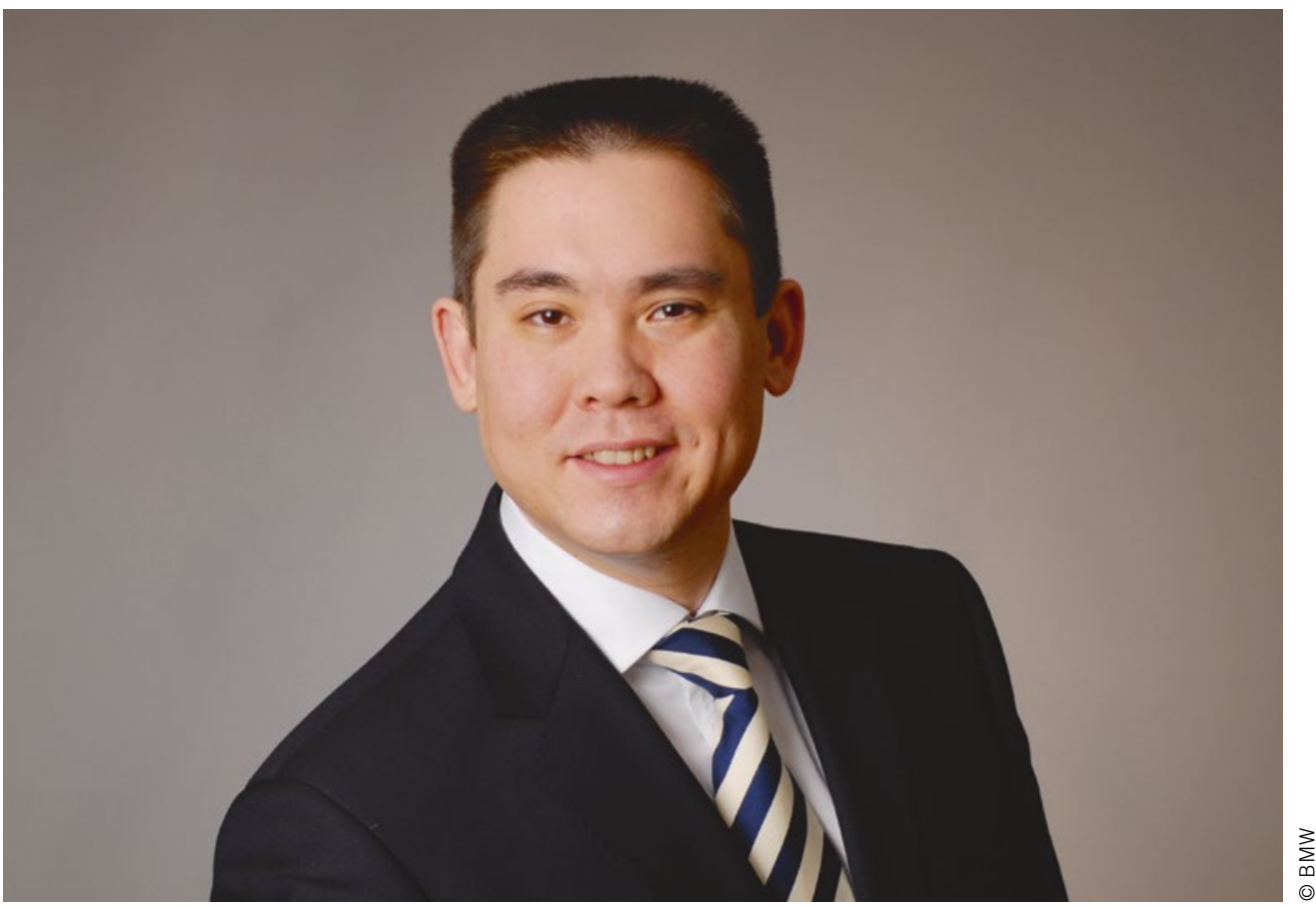

Martin Hauschild

Head of Traffic Management, BMW Group in München

\section{Mobilität der Zukunft - Revolution auf engstem Raum}

Mobilität geht alle an. Kaum ein anderes Grundbedürfnis ist so universell ausgeprägt wie das Bedürfnis, ständig in Bewegung zu sein - egal in welchem Alter und welcher Kultur. Nicht verwunderlich ist es darum, dass jeder zu Mobilität eine Meinung hat, wie sie sich verändert, welche Ausprägungen es in den Städten der Zukunft geben sollte und was von Angeboten der sogenannten New Economy zu halten ist.

Ein paar wenige Dinge stehen dabei fest. Die Urbanisierung schreitet voran, in Großstädten werden reine Luft und Platz zu kostbarsten Gütern. Das bedeutet, dass wir vorhandene Ressourcen effizienter nutzen müssen! Nun ist das keine sonderlich neue Erkenntnis. Eine bereits heute zu beobachtende Entwicklung könnte künftig eine sehr wichtige Rolle spielen: Die sich ausbreitende Digitalisierung lässt Eintrittsbarrieren fallen und bietet damit neuen Spielern Zutritt auf das Spielfeld, das bisher nur wenigen vorbehalten war. Bisher war es Aufgabe von Stadtverwaltungen, Mobilität in der Stadt anzubieten und zu organisieren. Das typische Programm: Tram, Bus und Bahn, dazu noch ein Stück Individualverkehr.

Doch wer in den Großstädten dieser Welt unterwegs ist wird heute schon erkennen, dass nun auch ganz andere Player Angebote bereitstellen, die es bisher so nicht gegeben hat. Ob es Internetfirmen sind, die durch den Zugriff auf Handy-Betriebs- systeme Verkehrsdaten und Prognosen generieren, die qualitativ hochwertiger sind als jeder mühevoll in die Fahrbahn eingegrabene Messquerschnitt, oder ob es ein Fahrdienst ist, bei dem man mit einem einzigen App-Klick einen Fahrer bestellt, der einen komfortabler als U-Bahn oder Taxi ans Ziel bringt.

Das kann man nun gut finden oder auch nicht, aber klar ist, dass diese Anbieter immer ein wirtschaftliches Interesse verfolgen. Das ist insofern ein positiver Aspekt, als das diese Konzepte im Kern eine effiziente Nutzung vorhandener Ressourcen verfolgen beziehungsweise darauf angewiesen sind, sollen sie erfolgreich sein.

Die Zukunft wird nun zeigen, wie Stadtverwaltung und Politik auf die neuen Angebote reagieren. Zum einen bieten sie eine immense Chance, Mobilität in der Stadt zu erhalten und vielleicht sogar wirtschaftlich zu betreiben, zum anderen ergeben sich Gefahren, weil die Kontrolle über das Angebot zumindest teilweise aus der Hand gegeben wird. In jedem Fall steigen Komplexität und Wechselwirkungen zwischen den Treibern. Essenziell ist es, die „gut und böse“-Diskussion zu vermeiden und mit allen Anbietern den Dialog zu führen, um die richtigen Schlussfolgerungen zu ziehen. Verbände wie der VDI haben in Initiativen wie „Stadt Denken“ den offenen Dialog bereits begonnen. Mobilität geht eben alle an. 